\title{
A Imigração no Direito Internacional do Trabalho
}

\section{The Immigration in International Labour Law}

\author{
Márcia Regina Castro Barroso \\ Universidade Federal do Rio de Janeiro, \\ Rio de Janeiro/ RJ - Brasil \\ Elina Goncalves da Fonte Pessanha \\ Universidade Federal do Rio de Janeiro, \\ Rio de Janeiro/ RJ - Brasil
}

Resumo O fenômeno da imigração, embora sendo complexo e diversificado, de certo tem uma relação muito estreita com a temática do trabalho. Ser um imigrante é, sobretudo, estar à procura de melhores condições de vida, inserindo-se em uma nova realidade social. Tal inserção, tal integração passa, na grande maioria dos casos, pela esfera do trabalho. Nesse sentido, escolhemos uma instituição que exerce uma grande influência no mundo laboral, a Organização Internacional do Trabalho (OIT), para analisarmos suas iniciativas em relação à temática da imigração. Para tanto, analisamos três de suas Convenções - as de números 97, 118 e a 143 - que apresentam um importante arcabouço legislativo de proteção à atividade produtiva do imigrante. Além desse material, analisamos também a "Declaração da OIT relativa aos princípios e direitos fundamentais do trabalho", de 1998, e a "Declaração da OIT sobre a justiça social para uma globalização equitativa", de 2008, onde destacamos as considerações relativas à imigração.

Palavras-chave: Imigração. OIT. ProteÇÃo SOCIAL. 
Abstract The phenomenon of immigration, while complex and diverse, is closely related to the theme of the work. Be an immigrant is, in most cases, to look for better living conditions in a new social reality. And such integration is primarily in the sphere of work. We choose an institution that has a great influence on the world of work, the International Labour Organization (ILO), to analyze their initiatives in relation to the issue of immigration. To do so, we analyze three of its Conventions - of number 97, 118 and 143 - which provide an important legislative framework for protection of the productive activity of the immigrants. In addition to this material, we also analyze the "ILO Declaration on Fundamental Principles and Rights at Work," 1998, and the "ILO Declaration on Social Justice for a Fair Globalization," 2008, where we highlight considerations relating to immigration.

Keywords: IMMIGRATION. ILO. SOCIAL PROTECTION.

\section{1 - INTRODUÇão}

A Organização Internacional do Trabalho, uma instituição quase centenária, tem hoje 97 anos de existência e reúne 185 Estados-Membros - sendo o Brasil um dos signatários desde a sua fundação. Conta com um sistema de Convenções e de Recomendações que, uma vez ratificadas, constituem-se como fontes formais de direitos. Isso significa que um Estado-Membro, ao ratificar uma Convenção, integra-a à sua respectiva legislação nacional. Sendo assim, esse sistema acaba por se transformar em um instrumento normativo de grande monta, em especial por se referir a assuntos de interesse internacional.

Atualmente, das suas 189 Convenções, três são especificamente voltadas para a temática da imigração:

- Convenção no. 97 - "Trabalhadores Migrantes";

- Convenção no 118 - "Igualdade de Tratamento entre Nacionais e Estrangeiros em Previdência Social";

- Convenção $\mathrm{n}^{\circ} .143$ - "Convenção sobre as imigrações efetuadas em condições abusivas e sobre a promoção da igualdade de oportunidades e de tratamento dos trabalhadores migrantes"; 
Este trabalho, portanto, visa analisar a atuação da OIT em relação à imigração por meio da análise das Convenções mencionadas. Na primeira seção do trabalho fazemos uma reconstrução histórica da trajetória da instituição, onde destacamos a sua importância para o cenário laboral. A seguir, trazemos algumas considerações sobre as Convenções, relacionando-as ao contexto histórico de sua elaboração. Por fim, também apontamos as iniciativas atuais que estão se desenvolvendo em relação ao tema, em especial na formulação de uma política pública em torno da imigração.

\section{2 - A Organização Internacional do Trabalho e sua IMPORTÂNCIA NO CENÁRIO LABORAL}

A Organização Internacional do Trabalho foi criada em 1919, no processo de pacificação após a Primeira Guerra Mundial, com a Liga das Nações. Um mundo conturbado com o lastro de destruição da primeira guerra procurava recompor as suas bases diplomáticas, e nesse sentido a organização da própria atividade produtiva se constituiu como um pressuposto fundamental. Com a Conferência de Paz, em Versalhes, decidiu-se pela organização de uma "Comissão de Legislação Internacional”, cujo desdobramento foi a criação da OIT, visando uma ação conjunta nos assuntos relativos à organização da esfera produtiva. Nos documentos de época, como muito bem nos aponta Arnaldo Süssekind, as justificativas para tal iniciativa gravitavam em torno de três eixos: o da política, tendo em vista a questão da paz universal; a humanitária, visando criar condições de trabalho mais justas; e a econômica, visando fornecer elementos que atenuassem a questão da concorrência internacional e suas consequências nas condições sociais (SÜSSEKIND, 1987, p. 100).

Antes mesmo da criação da ONU e de outros organismos internacionais, a OIT acabou por, paulatinamente, fortalecer o seu modelo, cabendo aos escritórios nacionais a função de cooperação técnica nas diversas iniciativas geradas a partir da temática do trabalho. Ela promoveu uma renovação do Direito Internacional do Trabalho, e com o 
sistema de convenções e de recomendações tentou criar padrões de uniformização da regulação das relações de trabalho entre os Estados-Membros.

Com a criação da Organização das Nações Unidas (ONU) em 1945, cujo objetivo era substituir a Liga das Nações, a OIT passou a ser integrada ao seu sistema, tornando-se uma agência especializada. Atualmente, a OIT possui a sua sede em Genebra e conta com a atuação de 185 Estados-Membros.

No processo de remodelação institucional que se seguiu ao fim da segunda guerra mundial, a OIT foi inserida num debate que questionava o seu papel nesse novo cenário. Nesse período, as organizações internacionais estavam voltadas para temas como a manutenção da paz e a resolução de conflitos. A OIT, que desde sua Conferência Geral, realizada em 1944, na Filadélfia, havia retomado os valores já declarados em sua constituição inicial, reforçaria ainda mais a sua atualidade: a promoção da justiça social. E bem mais do que isso, a partir de então ampliou a sua competência, estendendo a sua pauta para além dos temas referentes às condições de trabalho e dos direitos previdenciários do trabalhador. Tal ampliação instaurou um direito internacional do trabalho que se aproximou de novas temáticas, como a pauta dos então denominados direitos humanos. Gênero, reforma agrária, populações indígenas, políticas de desemprego, a educação e a saúde do trabalhador, o meio ambiente, enfim, progressivamente novas demandas passaram a ser incorporadas à pauta de atuação da OIT, fornecendo novos parâmetros normativos e ideários aos Estados-Membros.

Um fator que favoreceu a manutenção do prestígio da instituição ao longo desses 94 anos de existência foi, entre outros, o fato de sua organização ter uma composição tripartite, com representantes do governo, dos trabalhadores e dos empregadores. Esse tripartismo esteve presente desde a sua fundação e permanece como um elemento que lhe fornece legitimidade, proporcionando um diferencial em seu caráter representativo. Além desse tripartismo, outro elemento importante se refere à promoção do chamado diálogo social que tem se tornado um grande chamariz no campo do ideário dessa instituição. Para além da 
questão da legitimidade, a OIT também cresceu em importância, principalmente por conta do alcance no âmbito jurídico, por meio de suas convenções. Uma vez ratificadas, elas se constituem como fonte formal de direito, gerando direitos subjetivos individuais. Portanto, tornam-se instrumentos normativos de grande monta, em especial por tratarem de assuntos de interesse internacional. As convenções são tratados multilaterais que precisam ter a ratificação dos Estados-membros para terem valor normativo. Uma vez ratificada, a convenção integra a respectiva legislação nacional (SÜSSEKIND, 1987, p. 174).

A grande "força" desse sistema acaba por se tornar também a sua maior "fraqueza". Muitas críticas têm sido feitas a esse processo, principalmente por conta das especificidades das legislações nacionais. Pode-se ratificar uma convenção que foi pensada em termos mais gerais, e que pode não atender às demandas de uma dada localidade. Outra questão que se coloca se refere aos instrumentos de controle da aplicação desse instrumento normativo. Arturo Bronstein, em seu livro "Derecho Internacional y Comparado del Trabajo" (2010), propõe uma solução por meio do fortalecimento de Tribunais Internacionais. Embora seja uma solução possível de ser efetivada, ainda estamos longe de vermos a sua difusão. De toda forma, ao longo de todo o século XX a OIT foi crescendo em importância no cenário laboral internacional e, com a sua estrutura tripartite, tem conseguido manter um trabalho diplomático de grande eficácia.

Com o processo de globalização e de transformações atuais no mundo do trabalho, a OIT se vê diante de novos desafios a serem enfrentados. Oscar Ermida Uriarte, ao refletir sobre a inter-relação entre os processos de globalização e as relações laborais (1999), comenta que o sistema tradicional do Direito do Trabalho tem passado por significativas mudanças, principalmente por conta das transformações na própria organização produtiva. Nesse sentido, destaca a emergência do que ele chamou de "re-regulação internacional", que se efetiva por intermédio de convênios internacionais do trabalho, os grandes Pactos e Declarações de Direitos Humanos e as chamadas Cartas Sociais. A OIT, por gerar uma rede normativa universal, tem proeminência nesse 
processo. Entretanto, segundo Ermida Uriarte, esse processo, se por um lado proporciona um salto qualitativo pela universalização de certos princípios, por outro, para atender a uma demanda da própria organização do trabalho, e garantir condições mínimas de proteção social, acaba, de certa forma, colaborando para a expansão do processo de flexibilização das relações laborais.

Assim, nas décadas de 1980 e 1990, o grande desafio para essa instituição se dava no sentido de ser capaz de apresentar uma nova visão de mundo que conciliasse um programa social internacional frente aos interesses econômicos da época. Nesse contexto, emergiu o debate sobre a introdução de cláusulas sociais no comércio internacional. Estas seriam obrigações que deveriam satisfazer requisitos sociais específicos. Numa economia globalizada, pontos de tensão faziam que as organizações internacionais refletissem sobre suas atuações, principalmente em relação ao segmento empresarial e às organizações sindicais. Se por um lado a corrente dominante da esfera econômica exigia uma liberalização do mercado, por outro, representantes sindicais pressionavam, alertando para os efeitos nocivos que tal política econômica poderia acarretar, principalmente no que se refere à proteção social e à garantia de empregos.

A partir de então, um grande debate se instaurou na década de 1990 sobre a questão do Dumping Social ${ }^{1}$ e sobre o estabelecimento das cláusulas sociais. Este último tema, especialmente, se tornou central na medida em que era preciso definir que instituição seria encarregada de efetivar tais cláusulas. Particularmente, esse debate se acirrou após a criação oficial da Organização Mundial do Comércio (OMC) em 1995, que anteriormente recebia a nomenclatura de Acordo Geral de Tarifas e Comércio (GATT) ${ }^{2}$. Uma corrente de pensamento defendeu que as cláusulas sociais deveriam ser de responsabilidade da OMC. O princi-

\footnotetext{
Costuma-se definir o Dumping Social como uma prática de certas empresas que procuram aumentar os seus lucros, deslocando-se de um local para outro onde os salários são mais baixos e/ou os direitos dos trabalhadores são mais precários.

2 Não aprofundaremos a temática para investigarmos se a criação da OMC representou de fato alguma mudança significativa da instituição de regulação do mercado internacional, mas não podemos deixar de mencionar que tal iniciativa representa um esforço das entidades internacionais em dar uma resposta mais eficaz às transformações econômicas dessa época.
} 
pal argumento desta posição foi que a OMC seria capaz de estabelecer mecanismos de sanção aos países que não as respeitassem, atribuição essa impossível de se concretizar com a OIT, devido ao caráter de adesão e ratificação voluntária dos países membros e pela ausência de formas de controles internacionais.

O tema é bastante controverso e não aprofundaremos essa discussão neste trabalho. De todo modo, ele representa um questionamento da própria atuação da OIT e da sua eficácia como uma instituição capaz de manter padrões normativos numa sociedade cada vez mais globalizada. O que nos interessa aqui é percebermos alguns desdobramentos desse processo. $\mathrm{O}$ primeiro deles foi o entendimento dos organismos internacionais de que a normatização das cláusulas sociais deveria ficar ao encargo da OIT. O segundo foi a reafirmação dos próprios padrões mínimos de garantias trabalhistas internacionais, o que ficou conhecido como as "8 Convenções Fundamentais da OIT". Esses padrões mínimos foram reafirmados na 87. ' sessão da Conferência Internacional do Trabalho, em 1998, com a Declaração Relativa aos Princípios e Direitos Fundamentais no Trabalho. As Convenções Fundamentais são as seguintes:

- Convenção sobre o Trabalho Forçado, 1930 (n. $\left.{ }^{\circ} 29\right)$;

- Convenção sobre a Liberdade Sindical e a Proteção do Direito Sindical, 1948 (n. $\left.{ }^{\circ} 87\right)$;

- Convenção sobre o Direito de Sindicalização e de Negociação Coletiva, 1949 (n. $\left.{ }^{\circ} 98\right)$;

- Convenção sobre a Igualdade de Remuneração, 1951 (n. ${ }^{\circ} 100$ );

- Convenção sobre a Abolição do Trabalho Forçado, 1957 (n. $\left.{ }^{\circ} 105\right)$;

- Convenção sobre a Discriminação (Emprego e Profissão), 1958 (n. $\left.{ }^{\circ} 111\right)$

- Convenção sobre a Idade Mínima para Admissão a Emprego, 1973 (n. $\left.{ }^{\circ} 138\right)$;

- Convenção sobre a Proibição das Piores Formas de Trabalho Infantil e a Ação Imediata para a sua Eliminação, 1999 (n. $\left.{ }^{\circ} 182\right){ }^{3}$

Consultar o documento "A OIT no Brasil: trabalho decente para uma vida digna", 2012, p. 5. Disponível em: <http://www.oit.org.br/sites/default/files/topic/gender/pub/oit\%20no\%20brasil folder 809.pdf $>$ Acesso em: 10-03-2017. 
Segundo a ex-Diretora da OIT-Brasil, Laís Abramo, esta declaração estabelece que os Estados-membros da OIT são obrigados a respeitar as oito Convenções Fundamentais, independentemente de as terem ou não ratificado. Isso representa uma redefinição de padrões mínimos a serem considerados no mundo do trabalho, obedecendo a princípios que estariam acima de qualquer necessidade econômica. A proteção social - os direitos no mundo do trabalho - é apresentada como um princípio a ser mantido (ABRAMO, 2010, p. 32).

Vemos, portanto, que cada vez mais a Organização Internacional do Trabalho tem reforçado o seu papel diplomático de defensora dos direitos e princípios fundamentais voltados para a temática do trabalho. Após fazermos esse panorama acerca da atuação da OIT no mundo laboral, falaremos na próxima secção especificamente sobre suas convenções relativas à temática da imigração.

\section{3 - ConVEnÇões da OIT SOBRE A MIGRAÇÃo}

Conforme já comentamos, as três principais Convenções da OIT que tratam diretamente do tema da imigração são as de números 97 , 118 e 143.

As três convenções aqui tratadas, embora tenham sido aprovadas pela Conferência Internacional do Trabalho em momentos distintos, possuem alguns elementos em comum. O principal deles se refere ao delicado e diplomático papel da OIT no que diz respeito a dois princípios básicos: em relação à regulação mínima das condições para o exercício do trabalho migrante e, ao mesmo tempo, a garantia da livre circulação dos trabalhadores. Sendo assim, procurando respeitar as legislações específicas de cada país membro, a instituição incentiva a construção de um arcabouço legislativo internacional de modo a favorecer a proteção social e assegurar a liberdade individual. Além da utilização dos instrumentos normativos, a OIT também procura exercer influência sobre os organismos oficiais de emprego para que estabeleçam e respeitem os acordos multilaterais e bilaterais pertinentes.

Outro aspecto importante que a Organização Internacional do Trabalho procurou enfrentar se refere à questão da igualdade de tratamen- 
to entre os trabalhadores migrantes e os nacionais. $\mathrm{O}$ tema é bastante complexo. Entretanto, para alcançar uma legitimidade, a OIT lançou mão do pressuposto da existência de direitos fundamentais que deveriam ser compreendidos numa posição, ou melhor dizendo, num patamar que ultrapassasse, de certa forma ${ }^{4}$, as fronteiras nacionais. Esses direitos fundamentais, que posteriormente, com a Declaração de 1998 seriam explicitados, já estavam delineados em seus pressupostos básicos, como os de garantia das mínimas condições de trabalho e vida e o direito da liberdade individual.

Analisemos agora as Convenções apontando seus principais aspectos.

\section{Convenção 97 - "Trabalhadores migrantes"}

Elaborada na $32^{\mathrm{a}}$ Reunião da Conferência Internacional do Traba1ho, em 1949, essa convenção possui a característica singular de ter se constituído como o primeiro instrumento normativo da OIT em relação à temática específica da migração no plano do direito internacional. Inicialmente, destacamos o período histórico no qual ela se insere. No período pós-Segunda Guerra Mundial, essa convenção lança mão de uma regulamentação da mão de obra migrante, numa Europa marcada pelas consequências trágicas desse conflito. Esse foi um momento especial de circulação de pessoas e a OIT chamou para si a responsabilidade de regular internacionalmente esse conturbado mercado de trabalho.

Primeiramente a Convenção põe em evidência a necessidade dos países membros colocarem à disposição todas as informações sobre as políticas e a legislação nacional em relação aos migrantes. Dentro do contexto das instituições públicas nacionais, deveriam manter um serviço gratuito de modo a prestar auxílio aos trabalhadores, amparando-os em suas necessidades básicas. A Convenção também destaca a necessidade do controle em torno de propagandas relacionadas à imigração, de modo que evitem a indução a atitudes equivocadas.

A questão da equivalência de tratamento em relação aos nacionais estava condicionada à situação de legalidade do migrante. Sendo assim,

4 Dentro dos limites das políticas nacionais em relação à migração legal. 
não tendo impedimento de exercer a sua atividade laboral, o migrante deveria ter, por parte dos Estados membros, a proteção social. Tal proteção se referia à proteção médica, ao direito de se filiar a organizações sindicais e de gozar das vantagens das convenções coletivas de trabalho, às condições de habitação e ainda à possibilidade de remessa de parte de seus ganhos ao exterior.

A respeito da definição do trabalhador migrante, esta é apresentada no artigo de número 11, que diz:

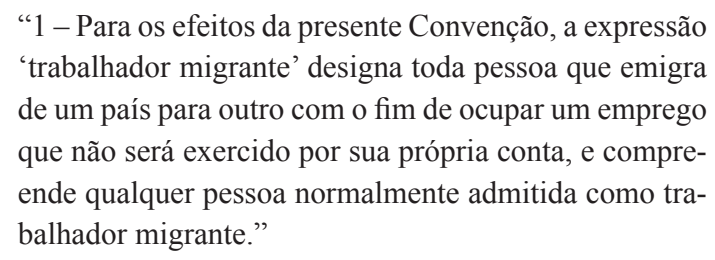

Dessa forma, vemos que esta convenção trata do trabalhador migrante dentro dos limites legais estabelecidos e que visa garantir as condições mínimas de exercício do trabalho em relação à saúde, habitação, liberdade de circulação e proteção social por parte das políticas nacionais.

O Brasil ratificou esta convenção e ela passou a ter vigência nacional em 1966.

\section{Convenção 118 - "Igualdade de tratamento entre nacio- nais e estrangeiros em Previdência Social"}

Esta convenção, aprovada na $46 .^{\mathrm{a}}$ reunião da Conferência Internacional do Trabalho, em Genebra, entrou em vigor no ano de 1964, e apresenta um instrumento normativo mais detalhado em relação à temática da previdência social.

Nesse sentido, como o próprio título sugere, a grande questão é sobre a igualdade de tratamento dos migrantes em relação aos nacionais. Os ramos da previdência que são tratados pela convenção são os seguintes:

a) Assistência médica;

b) Auxílio doença;

c) Prestações de maternidade; 
d) Aposentadoria por invalidez;

e) Aposentadoria por velhice;

f) Pensão por morte;

g) Prestações em caso de acidentes de trabalho e doenças profissionais;

h) Seguro desemprego;

i) Salário-família.

As exceções são às relacionadas a pensões por morte, que poderão estar sujeitas às condições de determinados prazos estabelecidos pela convenção.

Já em relação à garantia da aposentadoria, o art. 5. é enfático:

\begin{abstract}
"Além das disposições do art. 4, qualquer membro que tenha aceitado as obrigações da presente convenção para um ou vários dos ramos da previdência social de que trata o presente parágrafo deverá assegurar a seus próprios nacionais e aos nacionais de qualquer outro membro que tiver aceito as obrigações da referida convenção para um ramo correspondente em caso de residência no estrangeiro, o serviço de aposentadoria por invalidez, de aposentadoria por velhice, de pensão por morte e de auxílios funerais, assim como o serviço de rendas de acidentes de trabalho e de doenças profissionais, sob reserva das medidas a serem tomadas para esse fim, sempre que necessárias, de acordo com as disposições do art.8."
\end{abstract}

A convenção 118 também apresenta, de forma clara, a preocupação da OIT em estabelecer um patamar mínimo de direitos. Em seu art. $9^{\circ}$, por exemplo, este aspecto é reforçado quando diz que os Estados-membros podem derrogar a presente convenção, desde que não cause prejuízo aos outros membros, e que os direitos das legislações nacionais sejam ao menos tão favoráveis quanto os apresentados pela convenção.

O Brasil também ratificou esta Convenção e a mesma passou a ter vigência no ano de 1969. 


\section{Convenção 143 - "Sobre as Imigrações efetuadas em con- dições abusivas e sobre a promoção da igualdade de opor- tunidade e de tratamento dos trabalhadores migrantes"}

Aprovada no ano de 1975 , na $60 .^{\text {a }}$ reunião da Conferência Internacional do Trabalho, em Genebra, esta convenção apresenta, para um mundo do trabalho cada vez mais globalizado, uma linguagem mais complexa do que as outras convenções mencionadas, do ponto de vista de uma visão humanista mais elaborada. Além da questão da igualdade de tratamento, que foi exaustivamente mencionada nas anteriores, nessa convenção é destacada a questão dos direitos fundamentais do homem e de todos os trabalhadores migrantes. Nesse sentido, a OIT reforça a ideia de que o trabalho humano não é uma mercadoria e deve ser compreendido a partir de uma relação social mais ampla, em que pese a dignidade da pessoa humana. Das três convenções aqui mencionadas, esta é a única que ainda não foi ratificada pelo Brasil. ${ }^{5}$

Outro aspecto que podemos observar se refere à determinação de cooperação dos Estados-membros na erradicação das migrações clandestinas e do emprego ilegal dos imigrantes, conforme elucida o art. 3. Sendo assim, a troca de informações entre os Estados-membros torna-se uma estratégia fundamental. Em seu art. 6, a convenção enfatiza o combate ao tráfico ilegal:

\footnotetext{
"1 - No âmbito das várias legislações nacionais, deverão ser tomadas disposições para uma detecção eficaz de emprego ilegal de trabalhadores migrantes e para a definição e aplicação de sanções administrativas, civis e penais, incluindo penas de prisão, no que diz respeito a emprego ilegal de trabalhadores migrantes e à organização de migrações com fins de emprego que impliquem os abusos definidos no artigo 2 da presente Convenção e ainda a assistência prestada conscientemente a tais migrações, com ou sem fins lucrativos".
}

5 A Comissão Tripartite de Relações Internacionais aprovou em 2008 o encaminhamento da Convenção n 143 para o Congresso Nacional ratificá-la. Ver: <http:// portal.mte.gov.br/imprensa/ministerio-encaminha-a-convencao-n-143-da-oit-para-ratificacao.htm> Acesso em 16-06-2015. 
Ainda complexificando a questão da equidade, a OIT nesta convenção declara que um trabalhador migrante em situação legal não pode ser considerado em situação irregular pela simples perda do emprego, e esta, por si só, não deverá acarretar a revogação da sua autorização de residência e de trabalho. Em consequência, deverá ter o mesmo tratamento em relação aos nacionais no que diz respeito às garantias relativas à segurança de emprego, à reclassificação e à readaptação. Além disso, destaca-se que a migração de trabalhadores devida a condições do mercado de emprego deveria ser efetuada sob a responsabilidade das agências públicas de emprego, segundo os acordos multilaterais e bilaterais pertinentes, principalmente no que se diz respeito à livre circulação dos trabalhadores.

Um ponto que gostaríamos de destacar se refere à questão da promoção, por parte dos Estados-membros, de medidas que visem encorajar programas de educação, de modo a garantir aos trabalhadores migrantes o conhecimento mais completo possível da política adotada, dos seus direitos e obrigações, bem como, de todas as iniciativas que se destinam a lhes prestar assistência.

Além das três Convenções mencionadas, poderíamos também citar a existência de outras que, de certa forma, tratam, mesmo que indiretamente, da questão da imigração. Nas Convenções de número $111^{6}, 156$ e 181, também constam artigos que visam combater a discriminação na área de trabalho. Nesse sentido, é tida como atitude discriminatória, qualquer distinção, exclusão ou preferência, feita com base em raça, cor, sexo, religião, opinião pública, ascendência nacional ou origem social que vise impedir a igualdade de tratamento em matéria de emprego. ${ }^{7}$ Sendo assim, o trabalhador migrante não deveria ser discriminado e deveria ter as mesmas condições de tratamento dos nacionais.

Atualmente, no Brasil, a Organização Internacional do Trabalho assinou uma Declaração Conjunta com o Ministério do Trabalho e Emprego, no ano de 2008, relativa à Cooperação na área de Migrações La-

6 Ratificada pelo Brasil em 1965.

7 Ver convenção da OIT $n^{\circ} 111$, artigo $1^{\circ}$. 
borais. Por meio dessa declaração, ambas as instituições estabeleceram as bases de um trabalho compartilhado para a promoção e construção de políticas migratórias no marco das metas voltadas a trabalhadores migrantes estabelecidas na Agenda Hemisférica do Trabalho Decente das Américas.

\section{CONSIDERAÇões FINAIS}

Neste trabalho, procuramos elucidar o papel que a Organização Internacional do Trabalho tem exercido no cenário laboral e apontamos alguns aspectos de sua influência. Destacamos a questão dos seus instrumentos normativos por dinamizarem o Direito Internacional do Trabalho e por apresentarem uma proposta de construção de um patamar mínimo de direitos. Nesse sentido, trouxemos a análise de três Convenções que tratam especificamente sobre o tema da imigração e o que nos fica claro é a preocupação da OIT com a questão da igualdade de tratamento entre os migrantes e os nacionais. Este aspecto foi amplamente comentado nessas convenções e indica a permanência em nossas sociedades de uma visão preconceituosa e discriminatória dos trabalhadores que porventura estiverem exercendo suas atividades longe do seu país de origem. Mesmo atuando nos limites legais estabelecidos, a OIT destaca que não deve haver a separação em matéria de direitos entre esses trabalhadores. Propõe, assim, uma visão humanista que está além de uma visão contratual da relação de trabalho. Uma visão humanista que leve em consideração a existência de princípios básicos a serem seguidos pelos seus países membros. Em relação à temática do imigrante, a questão da discriminação torna-se um aspecto de extrema importância para essa instituição e para a formação de uma cultura de direitos. Nesse sentido, as relações sociais envolvidas na atividade do imigrante deveriam ser consideradas de forma ampla, de modo a garantir o pleno exercício de suas atividades nos diversos contextos em que estão inseridos. 


\section{REFERÊNCIAS}

ALMEIDA, Paulo Sérgio; PENNA, Rodrigo (org.) Contribuições para a Construção de Políticas Públicas voltadas à Migração para o trabalho. Brasília: Escritório Internacional do Trabalho, 2009.

BRONSTEIN, Arturo. Derecho Internacional y Comparado del Trabajo Desafios actuales. Genebra: OIT, 2010.

CRIVELLI, Ericson. Direito Internacional do Trabalho Contemporâneo. São Paulo: LTr, 2010.

SÜSSEKIND, Arnaldo. Direito Internacional do Trabalho. São Paulo: LTr, 1987.

URIARTE, Oscar Ermida. Globalizacion y relaciones laborales, 2001. Disponível em: <http://wilfredosanguineti.files.wordpress.com/2011/06/globalizacion-y-relaciones-laborales-oscar-ermida.pdf $>$. Acessado em: 17-05-2017.

Sites consultados:

- http://www.oit.org.br/

- $\quad$ http://www.ilo.org/

- http://portal.mte.gov.br/portal-mte/

Dados das Autoras:

\section{Márcia Regina Castro Barroso}

Doutoranda em Sociologia pelo Programa de Pós-Graduação em Sociologia e Antropologia da Universidade Federal do Rio de Janeiro (PPGSA-IFCS-UFRJ), Mestre em Sociologia e Direito pela Universidade Federal Fluminense (PPGSD-UFF). Bolsista de Doutorado do CNPq.

marciajose@ig.com.br

\section{Elina Goncalves da Fonte Pessanha}

Professora Titular da Universidade Federal do Rio de Janeiro e do Programa de Pós-Graduação em Sociologia e Antropologia - IFCS-UFRJ.

elina.pessanha@terra.com.br

Submetido em: 29-11-2016

Aceito em: 17-05-2017 